\title{
Proposta de recuperação florestal de uma área de pastagem no município de Agudos-SP com vista à apicultura
}

\author{
José Carlos de Deus Junior ${ }^{1}$ \\ Lucas Bertacini Viegas ${ }^{1}$ \\ Kelly Cristina Tonello ${ }^{2}$ \\ ${ }^{1}$ Discente Eng. Florestal, Universidade Federal de São Carlos - campus Sorocaba \\ Rodovia João Leme dos Santos, Km 110 - SP-264, Bairro do Itinga \\ Sorocaba - São Paulo - Brasil, CEP 18.052-780 \\ junior.jcd@hotmail.com, lucasbertacini@yahoo.com.br \\ ${ }^{2}$ Prof ${ }^{\mathrm{a}}$. Universidade Federal de São Carlos - campus Sorocaba \\ Rodovia João Leme dos Santos, Km 110 - SP-264, Bairro do Itinga \\ Sorocaba - São Paulo - Brasil, CEP 18.052-780 \\ kellytonello@ufscar.br
}

\begin{abstract}
Human actions such as urbanization and agriculture are the main activities generating processes of environmental impacts, which have negative consequences such as forest fragmentation, biodiversity loss and extinction of local species. Diversification in plantations of tree species for forest restoration provides a catalyst for ecological succession and one of the main pollinators are bees. The objective of this work is the reforestation of a pasture by plant species that will attract bees and increase honey production in the landowner. The proposed project will be held in Agudos city, São Paulo State-Brasil. The area to be retrieved consists of a grassland degradation, with 0.25 hectares. The planting scheme will be adopted in other row of pioneer species with non-pioneer species. All planting will be monitored within 10 years. It is expected that recovery of the forest enables an environment in its natural form. In order to observe the recovery site, will be recommended indicators of recovery such as: development, functional and environmental.
\end{abstract}

Palavras-chave: revegetation, degradation, melittophily.

\section{Introdução}

Ações humanas como urbanização, agricultura e outras atividades vêm, desde a época do descobrimento do Brasil, impactando consideravelmente os ecossistemas. A intensificação dessas atividades tem acarretado conseqüências como a fragmentação florestal, redução da biodiversidade e extinção de espécies locais (Kageyama \& Gandara, 2005). Umas das ferramentas utilizadas para conter a degradação do meio ambiente é a restauração ecológica dos ecossistemas naturais ou simplesmente restauração florestal. Essa ferramenta consiste na reabilitação do ecossistema as condições originais de flora, fauna, solo, clima e recursos hídricos.

Os ecossistemas degradados podem ser encontrados em duas condições, bem como, a autoregeneração e o degradado. A auto-regeneração é a fase, cujo ecossistema utiliza-se de recursos locais para manter a sua permanência como os bancos de sementes e rebrotações. Os ecossistemas degradados necessitam de uma intervenção antrópica, pois estes não conseguem se reabilitar sozinhos (Kageyama \& Gandara, 2005).

As florestas, quando em pé, prestam alguns serviços ao homem como a regularização do clima, proteção do solo, controle de pragas, polinização de culturas, e qualidade da vida nos rios (Kageyama \& Gandara, 2005). Especificamente, algumas espécies arbóreas podem propiciar 
incrementos no teor de nitrogênio do solo com associações de bactérias do gênero Rhizobium e Bradyrhizobium ou actinomicetos do gênero Frankia, acúmulo dos nutrientes e redistribuição dos mesmos e desenvolvimento da micro e mesofauna (Dias et al., 2007).

A biodiversidade nos plantios de espécies arbóreas nativas está entre os processos mais indispensáveis para a recuperação de áreas degradadas, os quais propiciam características de catalisadores da sucessão ecológica tais como a produção e a vinda de novas sementes, o estabelecimento de novas espécies, a atração da fauna, deposição de nutrientes do solo entre outros fatores (Rodrigues \& Gandolfi, 2000; Reis \& Kageyama, 2003).

Durante anos a apicultura vem contribuindo para a perfeita harmonia entre flora e fauna, sendo responsável pela perpetuação de espécies vegetais e também pelo aumento da produtividade em culturas agrícolas, devido a polinização. Além disso, esta atividade disponibiliza ao produtor rural produtos saudáveis como o mel, a geléia-real e o própolis, entre outros, complementando sua alimentação e possibilitando aumento de renda. O plantio de mudas de espécies frutíferas aliado à apicultura, são atividades econômicas que possuem grande interface com os recursos florestais, uma vez que a produção do mel está relacionada diretamente à existência de plantas que produzem flores: quanto mais plantas floridas maior a produção melífera. Nesse sentido a relação apicultura e recuperação florestal, resultam em uma equação onde ambos os componentes são essenciais e se complementam.

As abelhas, um dos principais agentes de polinização, são atraídas por espécies vegetais de forte odor, antese diurna, cores vivas como amarelo e violeta. Elas visitam as plantas em busca de néctar, pólen e outros óleos (Faegri \& Van Der Pij, 1979). Em um estudo realizado por Morellato (1991), o qual foi amostrado 265 espécies vegetais em um fragmento florestal foi encontrado um percentual de 39\% de polinização realizado por abelha. Além da Melitofilia, pode-se encontrar na flora polinização por borboletas ( psicofilia), aves ( ornitofilia), morcegos ( quiropterofilia) entre outros.

Diante do exposto, o objetivo deste trabalho é apresentar uma proposta de recuperação florestal de uma área de pastagem que se encontra em processo de degradação, privilegiando espécies vegetais nativas capazes de atrair abelhas (melitofilia) e forma a contribuir para a produção de mel de um proprietário rural, no município de Agudos-SP.

\section{Materiais e Métodos}

\subsection{Caracterização da área}

O trabalho será desenvolvido no sítio Donana, propriedade esta administrada por um pequeno agricultor o qual possui produção apícola em pequena escala. O sítio Donana está localizado no município de Agudos-SP, entre as coordenadas geográficas $47^{\circ} 4^{\prime} 39^{\prime}$ ' de longitude a oeste e $22^{\circ} 53^{\prime} 20^{\prime}$ ' de latitude sul e altitude média de 604 metros. Segundo a classificação de Koppen o clima é caracterizado como Cwa, com pluviosidade anual de 1100 a $1400 \mathrm{~mm}$ e temperaturas médias entre 16 e $19^{\circ} \mathrm{C}$.

A cidade de Agudos - SP é circundada pelo bioma Cerrado que possui fitofisionomia caracterizado por arbustos e árvores tortuosas com pequeno porte e casca muito grossa (Aquino \& Oliveira, 2006). 
A área a ser recuperada constitui uma pastagem, atualmente sem uso, em processo de degradação (Figura 1), já demonstrando focos de erosão e por conseqüência, perda de solo e nutrientes.

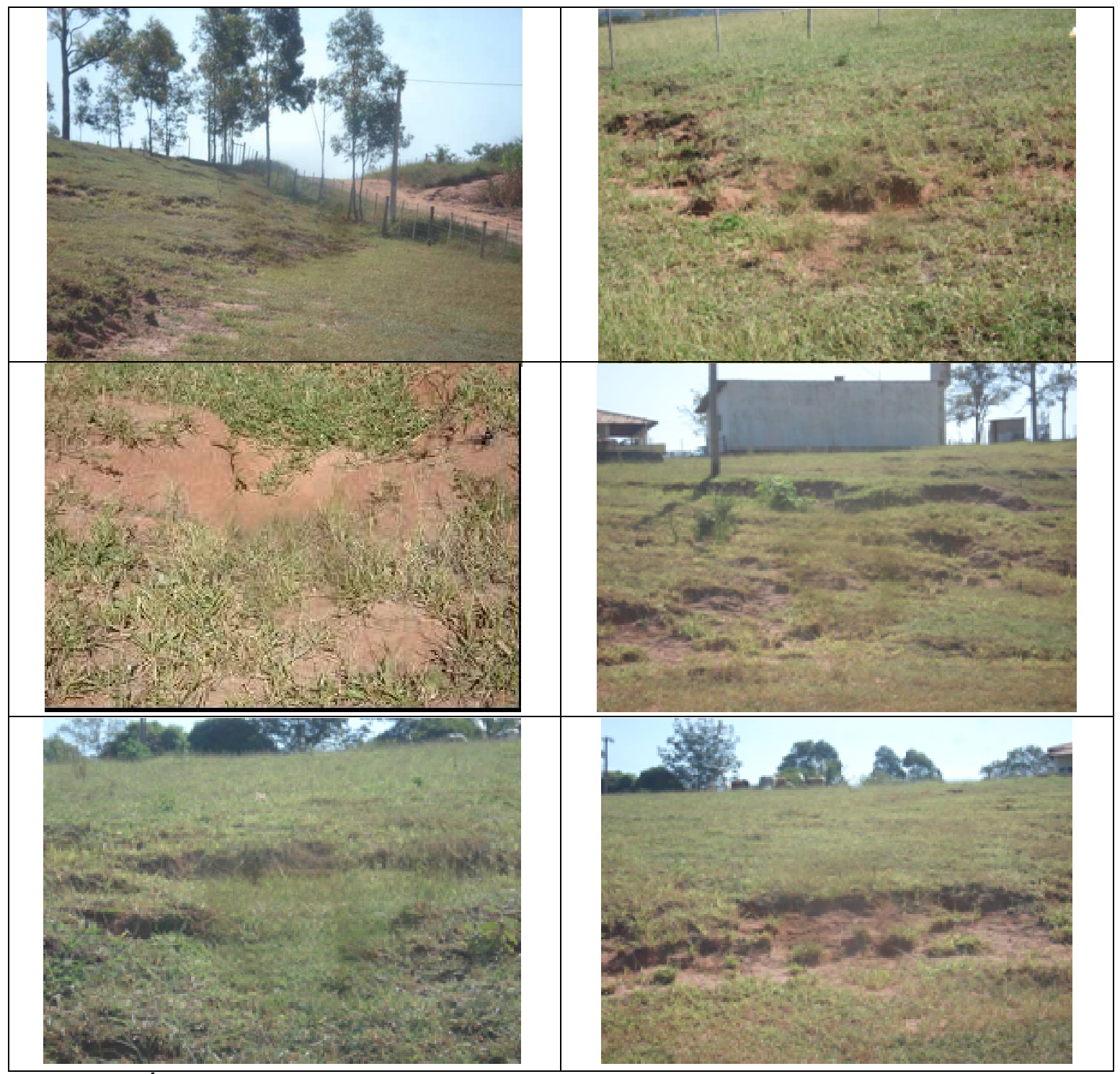

Figura 1. Área de pastagem a ser recuperada com espécies arbóreas nativas. Agudos-SP, junho de 2009.

\subsection{Metodologia do plantio}

\subsubsection{Escolha das espécies}

Para atender os objetivos do projeto, a escolha das espécies nativas irá abordar os seguintes aspectos: 
- Sombreadoras ou de cobertura - espécies de rápido crescimento (pioneiras ou secundárias iniciais), que terão a função de promover a rápida cobertura do solo e o sombreamento para as demais espécies. São também denominadas de "espécies de preenchimento" (Rodrigues \& Gandolfi 2000). Estas espécies, em geral de dispersão autocórica ou anemocórica, terão função distinta daquelas usadas na atração de fauna.

- Atração da fauna - espécies zoocóricas (dispersas por animais) e principalmente aquelas atrativas às abelhas, empregadas com o objetivo de atrair os animais para a área e promover a sua regeneração natural. Em relação ao grupo sucessional, podem ser pioneiras ou não-pioneiras (secundárias, secundárias tardias ou clímax).

- Adubadoras - espécies conhecidas por sua capacidade de fixação biológica de nitrogênio, interação com micorrizas ou por sua capacidade de derrama natural contribuindo com o aporte de biomassa na serrapilheira. Todas estas características contribuem para a melhoria da qualidade do solo.

- Espécies ameaçadas- consideradas ameaçadas ou em risco de extinção da formação florestal local.

\subsubsection{Distribuição das espécies}

O plantio será realizado numa área de 0,25 hectares, onde serão intercaladas linhas de pioneiras e não pioneiras, em espaçamento $2 \times 2 \mathrm{~m}$, totalizando 625 indivíduos (Figura 2). Nas linhas de plantio a serem estabelecidas, a distribuição das espécies no campo será efetuada com a instalação de uma linha contendo apenas espécies de pioneiras de cobertura seguida de outra contendo espécies não-pioneiras, de preferência, com a função de atração à fauna, adubadoras e/ou ameaçadas. $\mathrm{Na}$ linha de espécies de rápido crescimento também serão incluídas espécies atrativas à fauna e adubadoras. Dessa forma serão distribuídas em toda área espécies com a função de aumentar a diversidade, atrair a fauna e melhorar a qualidade dos solos.

Com fins de proteção (quebra-vento) e paisagismo, será realizado o plantio de espécies exóticas na extensão da bordadura frontal do sítio. Para isso, serão utilizados 200 indivíduos arbóreos de Eucalyptus sp.

\subsubsection{O Plantio}

Para minimizar os impactos ao solo e ocorrência de erosão, será adotada a técnica de cultivo mínimo, evitando-se o uso de maquinários em grande intensidade. O preparo do solo será feito de forma manual por meio de abertura de covas com profundidade de aproximadamente $40 \mathrm{~cm}$ nas linhas de plantio, onde se pretende também adotar a manutenção dos remanescentes dos indivíduos regenerantes. O controle de invasoras será realizado pelo uso de herbicidas ou capina manual ao longo do primeiro ano. Novas capinas serão efetuadas de acordo com a necessidade.

Para a adubação de base e cobertura, será realizada uma coleta de amostras do solo, que serão encaminhados ao laboratório de solos da UFSCar-Sorocaba para sua análise físico-química no início e ao final do projeto, obtendo-se dados de quantificação de alumínio, cálcio, magnésio, fósforo, potássio, nitrogênio, carbono, matéria orgânica e $\mathrm{pH}$. Esta análise será utilizada bem 
como para orientar a adubação base e de cobertura, mas também para efeitos de monitoramento do projeto.

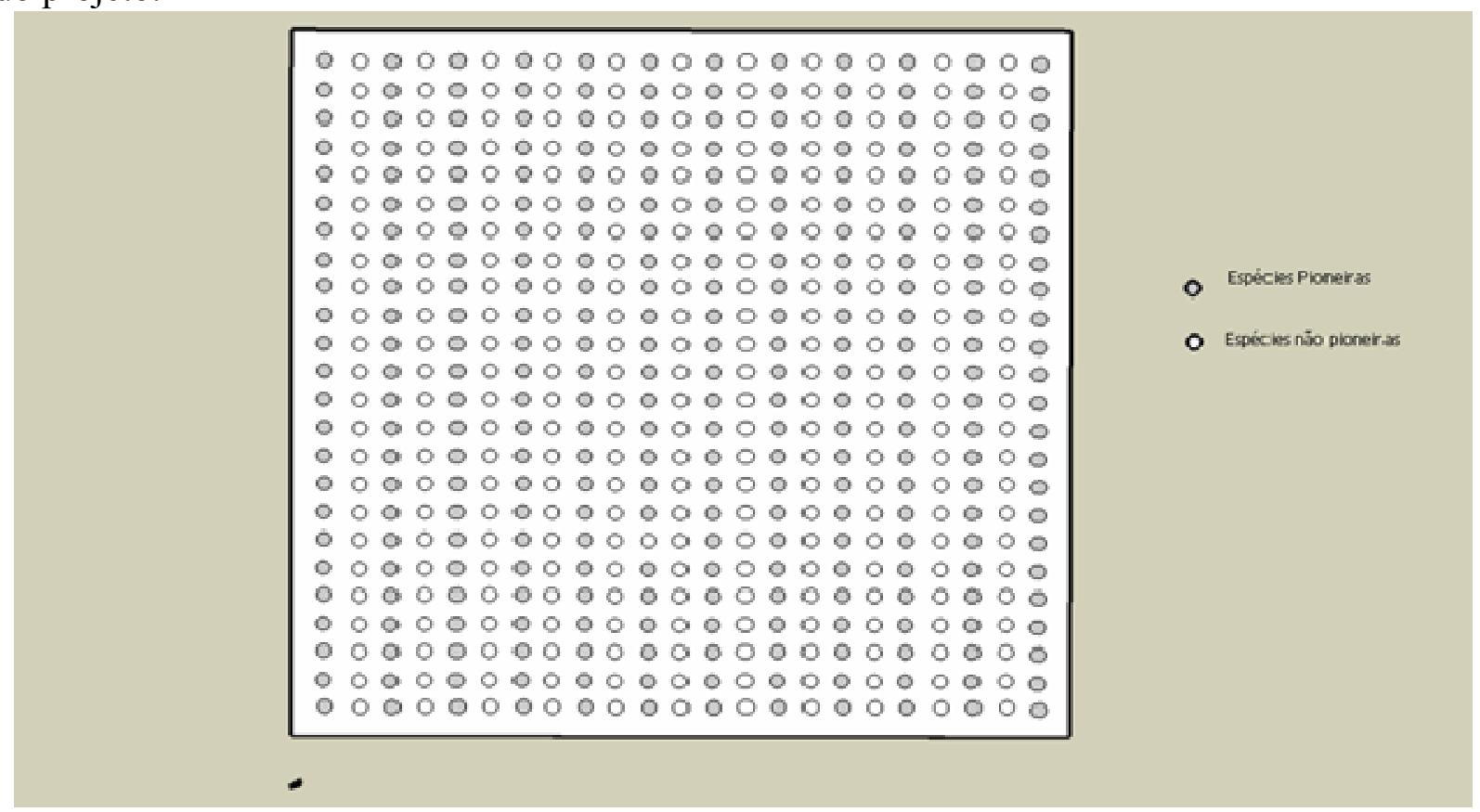

Figura 2. Croqui do esquema de plantio de espécies pioneiras e não pioneiras com espaçamento $2 \times 2$ metros.

\subsubsection{Controle de formigas}

O controle das formigas cortadeiras, principalmente as saúvas, será a primeira atividade operacional realizada na área destinada ao plantio. Para isso, será utilizada a isca granulada à base de Sulfluramida $0,01 \%$ na proporção de 10 gramas/olheiro. Trata-se do método mais utilizado atualmente em florestas, devido à facilidade de aplicação, à baixa toxicidade e, principalmente, aos bons resultados de controle obtidos.

Será realizado o controle inicial pré-plantio, 30 dias anterior ao plantio e, 7 dias antecedentes ao mesmo, seguido de repasses após a implantação das mudas.

\subsubsection{Tratos culturais}

O coroamento consiste na remoção (manual) ou no controle (químico) de toda e qualquer vegetação, em um raio de, no mínimo, $50 \mathrm{~cm}$ ao redor da muda ou do indivíduo regenerante. $\mathrm{Na}$ área de plantio, será realizado o coroamento manual com enxada, com remoção do mato a uma profundidade de cerca de $5 \mathrm{~cm}$ no solo, a fim de diminuir a rebrota das espécies competidoras.

\subsubsection{Replantio}

Após 60 dias do plantio, será realizada a atividade de replantio das mudas mortas. 


\subsection{Monitoramento do projeto}

O projeto será monitorado pelo período recomendado de 10 anos a partir do seu plantio. As atividades de monitoramento serão semestrais até o segundo ano de plantio, passando a intervalos anuais até o $5^{\circ}$ ano, quando poderão ser desenvolvidas a cada 2,5 anos.

\subsubsection{Indicadores de recuperação}

Para o acompanhamento da recuperação da área serão monitorados os seguintes indicadores:

a) indicadores de desenvolvimento - avaliação do desenvolvimento das mudas no plantio, aos seis e 12 meses. Posteriormente serão efetuados nos intervalos previstos anteriormente. Para tanto serão coletados dados de altura das mudas, diâmetro a altura do colo (até 24 meses), diâmetro a altura do peito (mudas altura $>1,5 \mathrm{~m}$ ), diâmetro da copa; mortalidade.

b) Indicadores funcionais: taxa de herbivoria, atração por abelhas, sanidade, ramificação;

c) Indicadores do ambiente: aporte de serrapilheira, banco de sementes, chuva de sementes, diversidade de artrópodes. Os indicadores serão coletados em áreas de parcelas permanentes, em subparcelas de $10 \times 10 \mathrm{~m}$.

\section{Resultados esperados}

Com o reflorestamento da área espera-se o restabelecimento das seguintes condições:

- Matéria orgânica, o qual permitirá a manutenção da atividade biológica e a melhoria das características químicas e físicas do solo,

- Incremento do teor de nitrogênio no solo

- Melhoramento da fertilidade dos horizontes superficiais,

- Desenvolvimento da meso, microfauna, microflora e microclima da área,

- Redução da erosão

- Aumento da polinização nos pomares

- Atração da fauna local, principalmente de espécies melíferas

\section{Referências bibliográficas}

DIAS, L. E.; FRANCO, A. A.; CAMPELLO, E. F. C. Fertilidade do solo e seu manejo em áreas degradadas. In: NOVAIS, R. F. Fertilidade do solo. Viçosa: Sociedade Brasileira de Ciências do solo, 2007.

FAEGRI, K. \& VAN DER PIJ. The principles of pollination Ecology. Pergamon press, Oxford. 1979.

KAGEYAMA, P. Y.; GANDARA, F.B. Restauração com espécies arbóreas nativas do convênio ESALQ/USP e CESP.In: GALVÃO,A. P. M.;PORFIRIO-DA-SILVA, V. Restauração Florestal: Fundamentos e estudos de caso. Colombo: Embrapa Florestas, cap3, p.47-58. 2005.

MORELLATO, L. P. C. Estudo da fenologia de árvores, arbustos e lianas de uma floresta semi-decídua no sudeste do Brasil. Tese de Doutorado. Universidade Estadual de Campinas, Campinas. 1991. 176p. 
REIS, A. \& KAGEYAMA, P. Y. Restauração de áreas degradadas utilizando interações interespecíficas. In: Kageyama, P. Y.; Oliveira, R. E.; Moraes, L. F. D.; Engel, V. L. \& Gandara, F. B. (org.) Restauração Ecológica de Ecossistemas Naturais. FEPAF, Botucatu, p. 91-110. 2003.

RODRIGUES, R. R.; GANDOLFI, S. Conceitos, tendências e ações para a recuperação de Florestas ciliares. In: Rodrigues, R. R.; Leitão Filho, H. F. Matas ciliares: conservação e recuperação. São Paulo: EDUSP/FAPESP, p. 235-48. 2000. 